\title{
Novel mutation in COL1A1 associated with osteogenesis imperfecta not compatible with life
}

\author{
Sarah A Wernimont MD PhD, ${ }^{1}$ Vani C Movva, MBBS, ${ }^{2}$ Asha Rijhsinghani, $\mathrm{MD}^{2}$
}

Keywords: Osteogenesis imperfecta, mutation, collagen, femur length

\begin{abstract}
Osteogenesis imperfecta $(\mathrm{OI})$ is a skeletal dyscrasia characterized by decreased bone strength and associated fractures. Over 95\% of autosomal dominant forms of this disease are associated with defects in the genes for collagen COL1A1 and COL1A2. ${ }^{1}$ The lethal type II disease has been identified antenatally by symmetrically shortened long bones and micromelia. Many reports have indicated that a femur length to abdominal circumference ratio ( $F L: A C)$ of less than 0.16 is predictive of lethality associated with $\mathrm{Ol}^{2,3}$ We report a case that presented at 20 weeks' gestation with shortening of the lower limbs, specifically a lagging femur length and FL:AC of < 0.16. On subsequent ultrasound examinations, progressive shortening of the femur as well as shortening of the long bones of the upper extremities was documented. The thorax appeared normal until 31 weeks. The FL:AC remained below 0.16 throughout pregnancy. Workup in the neonatal period identified a novel mutation in COL1A1. The neonate was able to breathe spontaneously at birth requiring minimal respiratory support for the initial 2 weeks and lived for 26 days.
\end{abstract}

${ }^{1}$ University of lowa Hospitals and Clinics, Department of Obstetrics and Gynecology, lowa City, lowa

${ }^{2}$ Perinatal Care Clinics, Department of Obstetrics and Gynecology, University of lowa Hospitals and Clinics lowa City, lowa

\section{Introduction}

Osteogenesis imperfecta (OI) is a heterogenous inheritable bone disease characterized by defects in bone matrix formation, which results in decreased bone strength and leads to bone fragility, deformity and short stature. About $95 \%$ of all cases of Ol are classified into 4 subtypes (I-IV) first described by Sillence et $\mathrm{al}^{4}$ and are associated with mutations that affect type I collagen genes, COL1A1 and COL1A2. ${ }^{1}$ Of the four main types of OI, type II is considered lethal with type III being severe. Both type II and type III OI are caused by dominant structural mutations in COL1A1 and COL1A2

Please cite this paper as: Wernimont SA, Movva VC, Rijhsinghani A. Novel mutation in COL1A1 associated with osteogenesis imperfecta not compatible with life. Proc Obstet Gynecol. 2014;4(2): Article 7 [ 6 p.]. Available from: http://ir.uiowa.edu/pog/. Free full text article.

Corresponding author: Asha Rijhsinghani, M.D., Department of Obstetrics and Gynecology, University of lowa Hospitals and Clinics, 200 Hawkins Drive, lowa City, lowa 52242-1080, Telephone: (319) 356-1945, FAX: (319) 353-6759, asharijhsinghani@uiowa.edu.

Financial Disclosure: The authors report no conflict of interest.

Copyright: (C) 2014 Rijhsinghani, et al. This is an open-access article distributed under the terms of the Creative Commons Attribution License, which permits unrestricted use, distribution, and reproduction in any medium, provided the original author and source are credited. 
which result in abnormal formation of collagen polymers and bone matrix disruption. ${ }^{1}$ Overall, OI affects one in 10,000 live births in the United States with the lethal type II phenotype making up $10 \%$ of these cases. ${ }^{1}$

Early prenatal diagnosis is critical to appropriately counsel patients on pregnancy options including pregnancy termination and in continuing pregnancies, the delivery strategies including whether or not a cesarean section would be advisable based on predicted survival. Previous reports have shown that ultrasonography can identify between 63 and $89 \%$ of OI antenatally. ${ }^{5}$ Findings during prenatal ultrasound include micromelia and bone demineralization as early as 14 weeks for type II disease in addition to shorted long bones ( $<5$ th percentile) associated with skeletal dyscrasia in general. ${ }^{6}$ The ratio of femur length to abdominal circumference has been previously shown to distinguish lethal skeletal dyscrasia including $\mathrm{Ol}^{2,3}$ One report notes that the mean age for diagnosing lethal skeletal dyscrasias based on FL:AC was 20.4 weeks, suggesting that this ratio may be used in antenatal counseling regarding options for termination; however, the specific diagnosis was only correct $65 \%$ of the time. ${ }^{7}$

\section{Case Report}

A 26 yo G1P0 woman was referred at 19 weeks gestational age (GA) due to abnormally shortened femurs noted on a local ultrasound examination (US). Antenatal integrated serum screening test was negative. Her family history was not contributory. On ultrasound examination, we confirmed the findings of shortened femur length (FL) of 18.2 $\mathrm{mm}$, which was <3rd percentile. Nasal bone measured $4.6 \mathrm{~mm}$, at the 2.5th percentile. Most of the other long bone measurements were lagging but still within the normal range for the gestational age (Table 1).

Table 1. Ultrasound findings: The measurements expressed in percentiles at the three ultrasound examinations performed at $19^{\circ}, 23^{\circ}$ and $314 / 7$ gestational weeks.

\begin{tabular}{|llll|}
\hline Gestational Age (weeks) & $19^{0}$ & $23^{0}$ & $31^{4}$ \\
\hline Estimated fetal weight in grams (percentile) & 218 & $396(14)$ & $1024(<10)$ \\
\hline Biparietal diameter in mm (percentile) & $46.8(80)$ & $52.5(23)$ & $85.3(94)$ \\
\hline Head Circumference in mm (percentile) & $159.6(30)$ & $198.7(8)$ & $288.7(29)$ \\
\hline Femur length in mm (percentile) & $\mathbf{1 8 . 2}(<3)$ & $\mathbf{2 6 . 5}(<3)$ & $\mathbf{3 1 . 2 ( < 3 )}$ \\
\hline FL:AC Ratio & $\mathbf{0 . 1 3}$ & $\mathbf{0 . 1 5}$ & $\mathbf{0 . 1 2}$ \\
\hline Thoracic circumference in mm (percentile) & $114(41)$ & $142(25)$ & $194(5)$ \\
\hline Abdominal circumference in mm (percentile) & $132.4(33)$ & $174.4(22)$ & $254.7(11)$ \\
\hline Humerus length in mm (percentile) & $23.9(5)$ & $30.2(<5)$ & $41(<5)$ \\
\hline Radius length in mm (percentile) & $20.2(5)$ & $25.3(5)$ & $24(<5)$ \\
\hline Ulna in mm (percentile) & $24.0(32)$ & $30.4(<5)$ & $40.4(<5)$ \\
\hline Tibia in mm (percentile) & $18.2(<5)$ & $23.2(<5)$ & Not measured \\
\hline Fibula in mm (percentile) & $19.2(<5)$ & $20.6(<5)$ & Not measured \\
\hline
\end{tabular}


The biparietal diameter (BPD), abdominal circumference (AC) and thoracic circumference (TC) measured normal for the gestational age. Both feet were at the 5th percentile. There was no evidence of fractures. Nuchal skin fold measured normal at $4.5 \mathrm{~mm}$.

The differential diagnosis included thanatophoric dwarfism, OI, and achondrogenesis. The patient was counseled that the findings were consistent with skeletal dysplasia. In view of the $\mathrm{FL}: A C$ ratio of 0.13 , this skeletal dysplasia would likely be lethal in the neonatal period. The patient was presented with options for antenatal genetic testing, expectant management as well as pregnancy termination. She desired expectant management and returned at 23 weeks for a follow up examination. At the repeat exam, the FL measured $26.5 \mathrm{~mm}$ ( $<5$ th percentile), $\mathrm{FL}$ : $A C$ ratio was 0.15 . The thorax measured at the 25th percentile and the AC was at the 22nd percentile. At 31 weeks and 4 days the FL:AC ratio continued to be abnormal at 0.12, and the chest circumference at this examination was < 5th percentile. The fetal skull appeared to have decreased mineralization, and the contour was easily distorted with light pressure applied on the fetal head via maternal abdomen with the transducer (Figure 1). For the first time, the ribs appeared flattened and shorter, but there were no obvious fractures in any of the long bones.

The patient experienced pretermpremature rupture of membranes at 33 weeks and 5 days. She received steroids for fetal lung maturation as well as ampicillin and azithromycin prophylaxis. At 34 weeks the patient went into spontaneous labor which was augmented with oxytocin. In view of the abnormal FL:AC ratio and high probability of neonatal death, fetal heart rate was monitored intermittently with plans for a vaginal delivery. A 1528 gram male infant was born with Apgar scores of 4,6 and 6 at 1,5 and 10 minutes respectively. The infant was born with spontaneous respirations. Multiple acute and healing fractures were noted on skeletal survey, suggesting OI. Genetic analysis showed a novel mutation in the COL1A1 gene c1363G $>A$ in exon 21 of chromosome 17 resulting in a missense mutation of Gly 455 Ser. Testing for FGFR3 gene was negative for thanatophoric dysplasia. In the NICU, the baby was reported to have a good cry and mild respiratory distress requiring $21 \%$ oxygen by nasal cannula. Starting age 2 weeks, the oxygen requirement gradually increased with a FiO2 of 25$30 \%$. On day of life 19 , apneic episodes increased and respiratory failure worsened requiring 100\% oxygen by cannula. The parents expressed their wishes to not pursue more aggressive life support measures, and the neonate died at age 26 days.

\section{Discussion}

OI is a skeletal dyscrasia that has both autosomal dominant and recessive modes of inheritance. Here, we describe a novel mutation of COL1A1 gene that was associated with lethal OI type II. It also highlights that isolated findings of early onset shortened femur bones with a decreased $F L: A C$ ratio can be critical components of antenatal counseling of the lethality of the condition and timely pregnancy management options. 


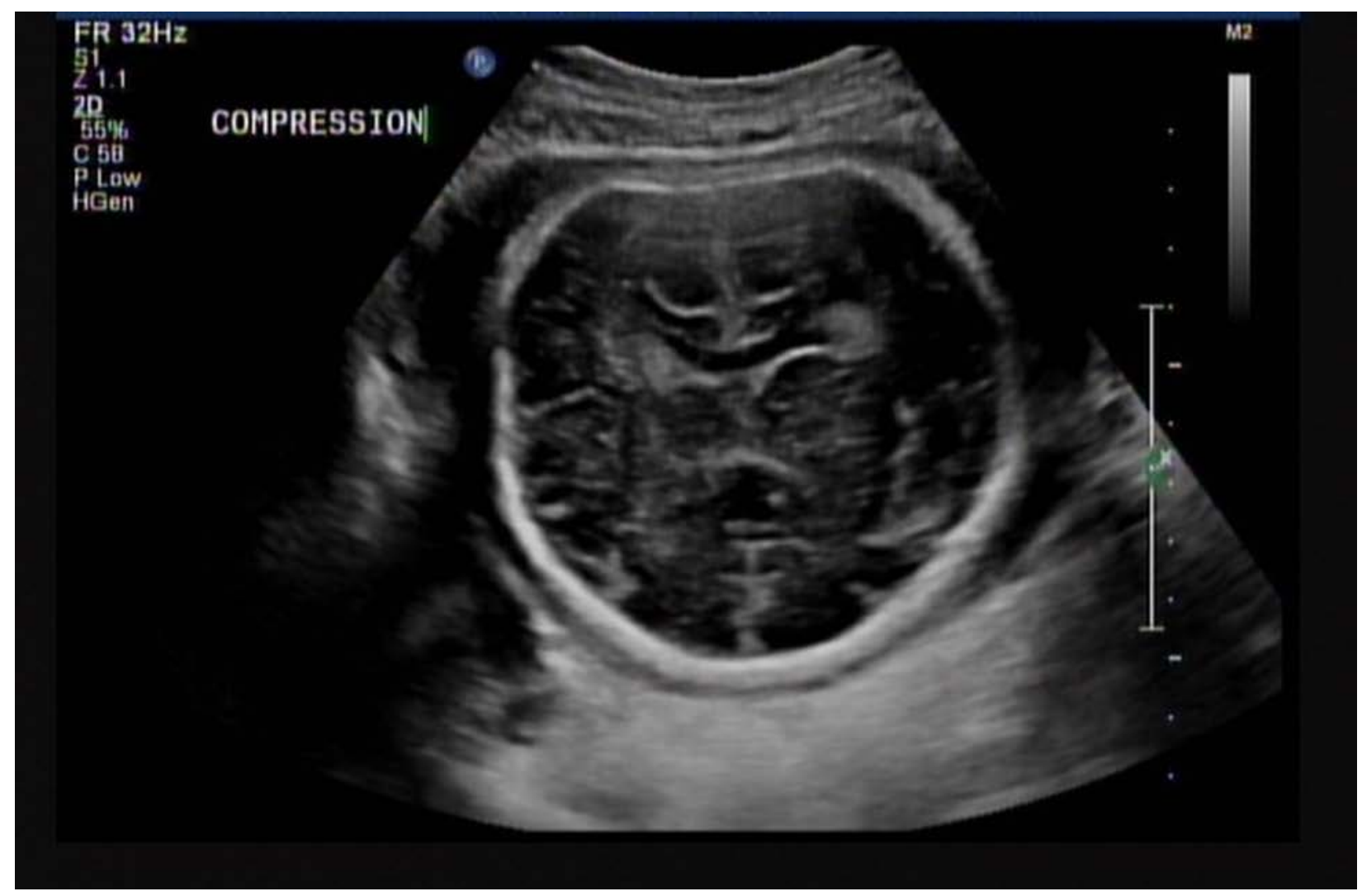

Figure 1. At 31 4/7 weeks gestation the fetal skull was easily compressed with light pressure via maternal abdomen

Type II OI is a lethal form of OI characterized by defects in collagen synthesis. Collagen is a heterotrimer of two alpha 1 and one alpha 2 chains which form an alpha helix. ${ }^{8}$ This helical arrangement requires the presence of the $(\mathrm{Gly}-\mathrm{X}-\mathrm{Y})$ repeat where $\mathrm{X}$ and $\mathrm{Y}$ are proline and hydroxyproline. ${ }^{1}$ Our reported new mutation is a missense mutation in the collagen 1A1 gene where glycine is replaced by a serine. This mutation interferes with Gly-X-Y repeats in the triple helical domain of the protein encoded by Col1A1 gene. The mutation likely interferes with appropriate formation of the collagen alpha helix. Cysteine and serine substitutions of the first position glycine have been described most frequently. ${ }^{1}$ Over 700 mutations of the COL1A1 gene have been reported to the Human Collagen Mutation database (http://www.le.ac.uk/ge/collagen/).

Overall, this mutation placed the infant in the type II spectrum of OI.

Ultrasonographic algorithms for diagnosis of skeletal dyscrasias have been described. ${ }^{9}$ As part of this diagnosis, femur length is considered the best indicator for detection of skeletal dyscrasias antenatally., ${ }^{5,10}$ In 
determining poor neonatal survival, the ratio of femur length to abdominal circumference has been reliably predictive. $^{2,3}$ In our case the initial FL:AC ratio at 19 weeks was 0.13 , though the rest of the long bones were not severely shortened and the head circumference (HC) and TC were normal at the 30th and 41st percentiles respectively. Over the course of the pregnancy, the $\mathrm{HC}$ remained in the normal range, as was the $\mathrm{TC}$, until 31 4/7 weeks, at which time the TC was at the 5th percentile. It is thought that death is usually caused by a narrowed thorax, which results in impaired lung development. ${ }^{11}$ In our case, the neonate was able to breathe spontaneously at birth, requiring minimal respiratory support until day of life 19, which is consistent with the prenatal thoracic findings of normal TC until 31 weeks gestation. The early and constant finding of a FL:AC ratio of $<0.16$, was the main prenatal finding which helped predict the lethality of this condition in a timely manner. This would support that if the thorax has normal growth until the 3rd trimester, the respiratory failure is less severe with relatively prolonged neonatal course.

This case highlights a new mutation of COL1A1 gene associated with lethal OI. It also confirms the reliability of the FL:AC ratio at mid-gestation in predicting lethality, as well as the importance of thoracic examinations in predicting the neonatal course.

\section{References}

1. Martin E, Shapiro JR. Osteogenesis imperfecta: epidemiology and pathophysiology. Curr Osteoporos Rep. 2007 Sep;5(3):91-7. 10.1007/s11914007-0023-z. PubMed PMID: 17925189.
2. Ramus RM, Martin LB, Twickler DM. Ultrasonographic prediction of fetal outcome in suspected skeletal dysplasias with use of the femur lengthto-abdominal circumference ratio. Am J Obstet Gynecol. 1998 Nov;179(5):134852. http://dx.doi.org/10.1016/S00029378(98)70158-9. PubMed PMID: 9822527.

3. Rahemtullah A, McGillivray B, Wilson RD. Suspected skeletal dysplasias: femur length to abdominal circumference ratio can be used in ultrasonographic prediction of fetal outcome. Am J Obstet Gynecol. 1997 Oct;177(4):864-9.

http://dx.doi.org/10.1016/S0002-

9378(97)70284-9. PubMed PMID: 9369835.

4. Sillence DO, Rimoin DL. Classification of osteogenesis imperfect. Lancet. 1978 May 13;1(8072):1041-2. DOI: 10.1016/S0140-6736(78)90763-8.

PubMed PMID: 76956.

5. Schramm T, Gloning KP, Minderer S, Daumer-Haas C, Hörtnagel K, Nerlich A, Tutschek B. Prenatal sonographic diagnosis of skeletal dysplasias. Ultrasound Obstet Gynecol. 2009 Aug;34(2):160-70. doi: 10.1002/uog.6359. PubMed PMID: 19548204.

6. Thompson EM. Non-invasive prenatal diagnosis of osteogenesis imperfecta. Am J Med Genet. 1993 Jan 15;45(2):201-6. DOI: 10.1002/ajmg.1320450210. PubMed PMID: 8456803.

7. Parilla BV, Leeth EA, Kambich MP, Chilis P, MacGregor SN. Antenatal detection of skeletal dysplasias. J Ultrasound Med. 2003 Mar;22(3):255-8; quiz 259-61. PubMed PMID: 12636325.

8. Ben Amor M, Rauch F, Monti E, Antoniazzi F. Osteogenesis imperfecta. Pediatr Endocrinol Rev. 2013 Jun;10 Suppl 2:397-405. . PubMed PMID: 23858623. 
9. Meizner I. Fetal skeletal malformations revisited: steps in the diagnostic approach. Ultrasound Obstet Gynecol. 1997 Nov;10(5):303-6. http://dx.doi.org/10.1046/j.1469-

0705.1997.10050303.x. PubMed PMID: 9444040.

10. Goncalves L, Jeanty P. Fetal biometry of skeletal dysplasias: a multicentric study. J Ultrasound Med. 1994 Dec;13(12):977-85. PubMed PMID: 7877211.

11. Merz E, Miric-Tesanic D, Bahlmann F, Weber G, Hallermann C. Prenatal sonographic chest and lung measurements for predicting severe pulmonary hypoplasia. Prenat Diagn. 1999 Jul;19(7):614-9. http://dx.doi.org/10.1002/(SICl)10970223(199907)19:7<614::AIDPD595>3.0.CO;2-P. PubMed PMID: 10419608. 